\title{
COMUNICAÇÃO
}

\section{DIAGNÓSTICO DA AUTOMAÇÃO NA PRODUÇÃO LEITEIRA ${ }^{1}$}

\author{
Diagnosis of automation in dairy farming \\ Juliana Vilela Lourençoni Botega², Roberto Alves Braga Júnior ${ }^{3}$, \\ Marcos Aurélio Lopes ${ }^{4}$, Giovanni Francisco Rabelo ${ }^{3}$
}

\begin{abstract}
RESUMO
Objetivou-se neste trabalho realizar um diagnóstico da automação na produção leiteira na região sul de Minas Gerais, enfatizando os tipos de automação existentes, melhoria do processo produtivo nas propriedades leiteiras com adoção da automação e as dificuldades enfrentadas para a sua implantação. A metodologia utilizada baseou-se na pesquisa qualitativa, por meio do estudo exploratório. Os resultados indicaram que existem várias opções de equipamentos que automatizam processos na produção leiteira. $\mathrm{O}$ estudo permitiu verificar também que a grande dificuldade enfrentada pelos produtores para automatizar as propriedades leiteiras é o alto custo dos equipamentos e a realidade da automação existe apenas para os grandes produtores de leite.
\end{abstract}

Termos para indexação: Adoção de tecnologia, agropecuária, bovinocultura leiteira.

\begin{abstract}
The purpase of this work was to carry out the diagnosis of automation in the dairy farming in Southern Minas Gerais, emphasizing the existing automation types, improvement of the productive process in milk properties with automation implementation, and the difficulties faced for its implantation. The methodology used was based on quality research by means of exploratory study The results indicated that several options of equipment exists that automate processes in milk production. The study also allowed the verification that the great difficulty faced by the producers to automate the milk properties is the high cost of the equipment, and that the automation reality is only for the greatest milk producers.
\end{abstract}

Index terms: Agriculture, dairy cattle, the implementation technology.

\section{(Recebido em 27 de abril de 2006 e aprovado em 19 de abril de 2007)}

No contexto da agropecuária brasileira, o leite ocupa posição de destaque pelo seu elevado valor de produção. Além disso, desempenha um papel importante no suprimento de alimentos e na geração de emprego e renda para a população brasileira. A cadeia produtiva do leite emprega, anualmente, cerca de 3,5 milhões de pessoas, dos quais um milhão e 300 mil são produtores, sendo aproximadamente 320 mil produtores comerciais e acima de 1000 empresas (VILELA, 2002).

De acordo com o Brasil (2004), nos últimos 10 anos, o Brasil aumentou sua produção de leite em $62 \%$, passando de 14,5 bilhões de litros para aproximadamente 23,5 bilhões, em 2004. Segundo o IBGE (2003), o Estado de Minas Gerais possui a primeira posição na produção nacional, respondendo por aproximadamente $29 \%$ do total de leite produzido no país.
A pecuária leiteira está vivendo um processo de modernização intenso. No setor primário, o processo de modernização não vai acontecer sem que os produtores se especializem. A modernização é a única alternativa para a continuidade da pecuária leiteira no Brasil (BRANDÃO, 2001).

A necessidade que as propriedades agrícolas têm apresentado nos últimos anos em relação à melhoria contínua nos seus níveis de qualidade, produtividade e competitividade passa também pelo desenvolvimento de soluções inovadoras que envolvem níveis diferenciados de automação (BANZATO, 2002). O panorama mundial aponta claramente para um futuro em que a agricultura dependerá inevitavelmente da automação. A automação poderá auxiliar profundamente na sustentabilidade, tanto do processo produtivo como do desenvolvimento econômico e social (EMBRAPA, 1996).

\footnotetext{
${ }^{1}$ Parte da dissertação do primeiro autor apresentada à Universidade Federal de Lavras para obtenção do título de mestre em Engenharia Agrícola. ${ }^{2}$ Doutoranda em Engenharia Agrícola - Departamento de Engenharia/DEG - Universidade Federal de Lavras/UFLA - Cx. P. 3037 - $37200-000$ - Lavras, MG - julourenconi@tpnet.psi.br

${ }^{3}$ Doutor em Engenharia Agrícola, Professor - Departamento de Engenharia/DEG - Universidade Federal de Lavras/UFLA - Cx. P. 3037 - $37200-000$ Lavras, MG - robbraga@ufla.br; giovannirabelo@yahoo.com.br

${ }^{4}$ Doutor em Zootecnia, Professor - Departamento de Medicina Veterinária/DMV - Universidade Federal de Lavras/UFLA - Cx. P. 3037 - $37200-000$ Lavras, MG - malopes@ufla.br
} 
Segundo Lopes (1997) a automação não está presente apenas nas indústrias, já chegou ao campo, podendo melhorar a produtividade e redução de erros. Esse autor cita ainda diversas tecnologias relacionadas à automação de atividades na pecuária de leite. De acordo com Faria (2001) muitas das tarefas de rotina de um sistema de produção de leite podem ser automatizadas. Os sistemas de automação voltados à produção leiteira evoluíram muito nos últimos anos. A tecnologia atual possibilita a construção de sistemas controlados bastante eficientes.

Objetivou-se neste trabalho realizar um diagnóstico da automação na pecuária leiteira no sul do Estado de Minas Gerais. Especificamente, buscou-se verificar os tipos de automação existentes na pecuária leiteira, verificar a adoção da automação por produtores de leite, avaliar a melhoria do processo produtivo nas propriedades leiteiras com adoção da automação e verificar as limitações de algumas propriedades do sul do Estado de Minas Gerais, para a introdução da automação.

Para verificar os tipos de automação existentes na pecuária leiteira, a adoção da automação por produtores de leite e para avaliar a melhoria do processo produtivo nas propriedades leiteiras com adoção da automação, foram realizados levantamentos de dados em fontes secundárias. Foram realizadas também entrevistas não-estruturadas individuais. Essas entrevistas foram realizadas com o objetivo de intensificar o conhecimento sobre o assunto, sendo as informações obtidas por meio de profissionais que atuam na cadeia produtiva de leite, como veterinários, fazendeiros, técnicos, mestres, etc.

Para verificar as limitações do uso da automação por produtores de leite foram analisadas quatro propriedades rurais e realizadas entrevistas com os proprietários. Vale ressaltar que a pesquisa realizada com os produtores resulta da necessidade de conhecer as características das limitações encontradas pelos produtores, na utilização da automação leiteira. As propriedades visitadas foram selecionadas de forma nãoprobabilística, intencional, levando em consideração a produção média diária situada acima de 250 litros de leite, consideradas grande produtoras de leite. Essa seleção também baseou-se na indicação de profissionais com experiência na atividade leiteira. Para preservar a integridade das propriedades pesquisadas, elas foram assim identificadas: Propriedade A, Propriedade B, Propriedade C e Propriedade D. As propriedades A, B, C e $\mathrm{D}$ possuem as seguintes produções diárias de leite tipo $\mathrm{B}$ : 4000 litros/dia, 3000 litros/dia, 9000 litros/dia e 1600 litros/ dia respectivamente.

Em relação aos tipos de automação existentes na pecuária leiteira foram constatadas uma gama de equipamentos disponíveis para o atendimento de todo o processo produtivo, desde o controle eletrônico, passando pela identificação de cio e terminando com o auxílio no processo de ordenha. Vários exemplos podem ser citados como: identificação eletrônica dos animais, detecção de cio, automação na sala de ordenha, limpeza automática dos equipamentos, robôs ordenhadores, resfriadores automatizados de leite além de outras atividades automatizadas e monitoradas através de sensores por um sistema computadorizado.

A identificação eletrônica de animais é um método seguro e confiável. Esse é o pré-requisito para o monitoramento, tratamento e cuidados individuais de cada vaca, que é um dos fatores importantes para a saúde e bom desempenho do rebanho. São vários os tipos de identificação eletrônica. A identificação mais utilizada em rebanhos leiteiros, mantidos em sistema intensivo de produção, é a utilização de colares eletrônicos. Um outro tipo de identificação eletrônica de animais é a identificação por microchip, conhecido também por transponder . Existem outros métodos de identificação eletrônica de animais como a utilização de brincos eletrônicos.

A detecção de cio aumenta a eficiência reprodutiva, produzindo um menor período de serviços e intervalos de parto. Para obter uma maior eficiência reprodutiva do rebanho, é necessária uma identificação (ou detecção) de cio eficiente e uma boa taxa de concepção. Vários são os métodos para melhorar a eficiência na identificação de cios como pedômetros, aparelhos eletrônicos, entre outros.

A automação de atividades, na sala de ordenha, é cada vez mais comum nas propriedades leiteiras, garantindo um processo harmonioso e rápido independente do tamanho do rebanho. Ela padroniza atividades que antes eram manuais e, portanto, passíveis de erros. O objetivo de todo produtor deve ser ordenhar eficientemente cada animal, em cada ordenha, independente do tamanho do rebanho, retirando o máximo de leite, no mínimo de espaço de tempo, sem prejudicar a saúde da vaca. Essa economia de tempo é muito importante, pois favorece uma boa esgota das vacas, aumenta a capacidade da ordenha (vacas/hora) e, conseqüentemente, do sistema como um todo além de maximizar o uso da mão-de-obra. As salas de ordenha podem ser de diversas formas. A seleção do tipo e o grau de automação do equipamento de ordenha depende do número de vacas em lactação, custo inicial e anual (capital disponível), disponibilidade de assistência técnica e da preferência do proprietário quanto à atenção individual por vaca e à eficiência de mão-de-obra.

A automação também está presente na limpeza e higienização dos equipamentos da ordenha e tubulação de leite. A limpeza dos equipamentos é um processo 
rigoroso e criterioso. É muito importante que a ordenha seja eficientemente limpa, preservando a alta qualidade do leite. O limpador automático de leite é um sistema de limpeza que economiza eletricidade, água, produtos e mão-de-obra, sem comprometer a perfeição da limpeza, tornando assim o processo de ordenha mais rápido e eficiente.

A ordenha robótica é um sistema inteligente, necessário para executar todas as tarefas que giram em torno da vaca. É voluntário porque é a vaca que decide a hora e quantas vezes quer ser ordenhada, fazendo tudo sozinha, sem intervenção humana. O sistema é completo, pois além da ordenha propriamente dita, ele tira e separa o primeiro leite, higieniza o úbere, desinfeta teta por teta, fornece ração e lava o piso por inundação.

A refrigeração na propriedade leiteira é um dos grande fatores contribuintes para a qualidade do leite. Quanto mais rápido for reduzida a temperatura, melhor será a conservação do leite. Para isto, utilizam-se tanques de expansão, que oferecem melhores condições para um acelerado resfriamento.

Em relação à adoção da automação por produtores de leite, foi verificado que poucos produtores utilizam automação nas suas propriedades, sendo que muito dos equipamentos verificados são importados, o que os torna de alto valor econômico para produtores em geral (Tabela 1). Nota-se pela Tabela 1 que o acesso à automação para produção de leite é quase uma exclusividade dos grandes produtores e, mesmo entre esses produtores considerados grandes, o investimento em equipamentos automatizados é limitado.

Em relação à melhoria do processo produtivo nas propriedades leiteiras, com adoção da automação, foram verificadas uma série de vantagens. Observa-se pela tabela 2, uma análise das vantagens da automação nas propriedades leiteiras. A automação facilita todo o processo produtivo e de coleta e análise de dados, principalmente em fazendas muito grandes.

Em relação às dificuldades para implantação de equipamentos voltados à automação nas propriedades leiteiras, o que se percebeu nas propriedades visitadas é que a limitação para alguns equipamentos, que melhoram a automação nas propriedades, é o alto valor de investimento. Existe um receio, por parte dos produtores, em contrair dívidas em razão das incertezas com relação ao retorno financeiro da atividade a médio prazo, uma vez que esses produtores investiram um capital alto em equipamentos básicos. Outra limitação percebida foi uma ausência de informações sobre os equipamentos e seus benefícios.

Tabela 1 - Análise da utilização da automação pelos produtores e origem dos equipamentos.

\begin{tabular}{|c|c|c|c|c|c|}
\hline Automação & Pequeno & Médio & Grande & Nacional & Importado \\
\hline Identificação eletrônica animais* & & & $\mathrm{X}$ & & $\#$ \\
\hline Brincos eletrônicos* & & & $\mathrm{X}$ & & $\#$ \\
\hline Colares eletrônicos* & & & $\mathrm{X}$ & & $\#$ \\
\hline Pedômetro* & & & $\mathrm{X}$ & & $\#$ \\
\hline Sensores de pressão* & & & $\mathrm{X}$ & & $\#$ \\
\hline Balança eletrônica* & & & $\mathrm{X}$ & $\#$ & $\#$ \\
\hline Ordenha Carrossel* & & & $\mathrm{X}$ & & $\#$ \\
\hline Ordenha Side-by-side* & & & $\mathrm{X}$ & & $\#$ \\
\hline Ordenha Espinha de peixe & & & $\mathrm{X}$ & \# & $\#$ \\
\hline Ordenha Tandem & & & $\mathrm{X}$ & $\#$ & $\#$ \\
\hline Extrator automático de leite & & & $\mathrm{X}$ & & \# \\
\hline Finalizador automático de leite* & & & $\mathrm{X}$ & & $\#$ \\
\hline Medidor eletrônico de leite* & & & $\mathrm{X}$ & & $\#$ \\
\hline Ordenha robótica & & & + & & $\#$ \\
\hline Pulsador eletrônico de leite & & & $\mathrm{X}$ & & $\#$ \\
\hline Resfriador de leite & $\mathrm{X}$ & $\mathrm{X}$ & $\mathrm{X}$ & $\#$ & $\#$ \\
\hline Limpeza automática & & & $\mathrm{X}$ & & \# \\
\hline
\end{tabular}

$\mathrm{X}$ :produtores que utilizam; * :pouco utilizado; + :ainda não existe no Brasil; \# :origem. 
Tabela 2 - Vantagens da utilização da automação nas propriedades leiteiras.

\begin{tabular}{|c|c|}
\hline Automação & Vantagens da utilização \\
\hline Identificação eletrônica de animais & $\begin{array}{l}\text { Melhora o gerenciamento produtivo e o monitoramento dos dados da } \\
\text { propriedade. }\end{array}$ \\
\hline \multicolumn{2}{|l|}{ Colares eletrônicos } \\
\hline Pedômetro & Melhora a eficiência reprodutiva da propriedade. \\
\hline \multicolumn{2}{|l|}{ Sensor de pressão } \\
\hline Balança eletrônica & Facilita o controle dos dados referentes ao peso do animal. \\
\hline Ordenhas & Melhora a qualidade do leite e diminui custos com mão-de-obra \\
\hline Extrator automático de leite & Melhora o manejo da ordenha, acabando com a sobre ordenha. \\
\hline Finalizador automático de leite & Possibilita uma ordenha completa do leite evitando-se o leite residual. \\
\hline Medidor eletrônico de leite & $\begin{array}{l}\text { Facilita o controle das lactações, pois faz a pesagem diária da produção } \\
\text { de leite das vacas e a transmite, automaticamente, ao sistema } \\
\text { informatizado. }\end{array}$ \\
\hline Ordenha robótica & Padronização dos processos. \\
\hline Pulsador eletrônico de leite & $\begin{array}{l}\text { Melhora o fluxo de leite durante a ordenha e faz uma massagem mais } \\
\text { eficiente nos úberes das vacas. }\end{array}$ \\
\hline Resfriador de leite & Melhora a qualidade do leite. \\
\hline Limpeza automática & Diminui o custo de mão-de-obra e padroniza a limpeza. \\
\hline Ambiência - zona de conforto & Melhora o desempenho produtivo e reprodutivo do rebanho. \\
\hline
\end{tabular}

Das quatro propriedades visitadas, todas elas possuem um nível de automação. Em relação à FIGURA 1 verificou-se nas quatro propriedades, que os produtores estão investindo mais em automação e limpeza automática da sala de ordenha. Nenhum dos produtores usa tecnologia de identificação eletrônica de animais. Nas propriedades C e D os proprietários estão usando protocolos de utilização de hormônios para inseminação artificial em tempo fixo, não utilizando identificação eletrônica de cios. Nenhuma das quatro propriedades investiu em identificação eletrônica de animais e nem em balança eletrônica; a identificação dos animais é feita através de brincos e a pesagem dos animais através de fita barimétrica. Nenhuma das propriedade investiu em sistemas automatizados em relação à ambiência ou alimentação automatizada.

O nível de automação está distribuído da seguinte forma: a Propriedade A é mais automatizada, com investimentos recentes nessa área. Possuía equipamentos como ordenha espinha-de-peixe, tanques de expansão e limpador automático de ordenha. Há um ano, aproximadamente, investiu em mais equipamentos como medidores eletrônicos e extratores automáticos de teteiras, melhorando o nível de automação da propriedade.

A propriedade $B$ está em processo de melhoramento, possuía equipamentos como sistema de ordenha canalizada e tanque resfriador. Está atualmente investindo em equipamentos como extratores automáticos de teteiras e medidores eletrônicos de leite. O proprietário também está investindo em estrutura física como um fosso para instalação de nova sala de ordenha, no sistema espinha-de-peixe.

A Propriedade $\mathrm{C}$ tem previsão para melhorar a automação da propriedade leiteira, no primeiro semestre de 2006. Possuía equipamentos como ordenha espinhade-peixe, tanques de expansão e limpador automático de ordenha. Em um primeiro momento, pretende aumentar a capacidade da ordenha existente e adquirir mais um tanque de expansão, de 6000 litros de capacidade. Segundo o proprietário, no momento em que alcançar a produção de 16000 litros/dia, programada para 2007, ele poderá avaliar a viabilidade de instalar extratores automáticos de teteiras, medidores eletrônicos de leite e cerca de aproximação. 


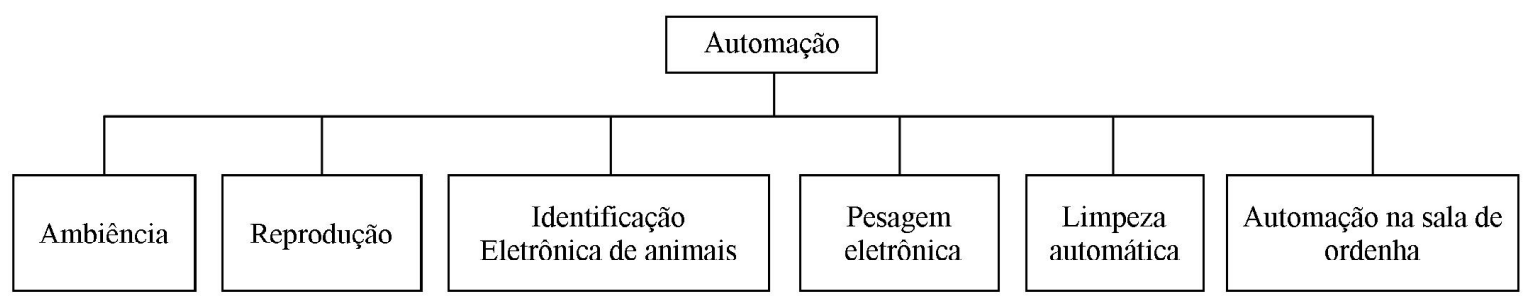

Figura 1 - Divisão da automação na produção leiteira em relação à investimentos.

A propriedade D não tem previsão para investir em automação e possui equipamentos como ordenha espinhade-peixe e tanque de expansão.

Todas as propriedades fornecem leite para laticínios tradicionais da região e o preço do leite geralmente varia com relação à quantidade e à qualidade de leite fornecido. Com relação à qualidade, as informações passadas pelos produtores indicam que todas as propriedades possuem uma boa qualidade do leite produzido, mesmo com diferentes graus de automação.

As quatro propriedades visitadas possuem como meta o aumento contínuo da produção de leite. Não existe um padrão de automação, cada produtor realiza investimentos de acordo com a necessidade considerada prioritária para seu sistema de produção e com sua capacidade de investimento. Cada uma possui as suas peculiaridades, fazendo com que, em alguns casos, a instalação de equipamentos automatizados tragam grandes vantagens; outras possuem outras prioridades que trariam mais vantagens econômicas e zootécnicas. Entre os motivos, que estão levando os produtores a investir em automação nas propriedades, estão a diminuição do custo com mão-de-obra, o monitoramento regular das atividades e a padronização dessas atividades.

Conclui-se, que existe uma grande disponibilidade de tecnologias voltadas à automação da atividade leiteira, e muitas tarefas de rotina de um sistema de leite podem ser automatizadas.

Ficou evidente que alguns fatores de ordem econômica apresentam-se como obstáculos ao processo de automação, como o alto custo de aquisição dos equipamentos, na maioria importados.

Ressalta-se que a automação dos processos, nas propriedades leiteiras, é uma realidade apenas para os grandes produtores de leite. Os resultados evidenciam que o processo de implantação da automação, nas propriedades leiteiras, é lento e gradativo, justificado pelas restrições de disponibilidade financeira para grandes investimentos. Ainda há um longo caminho a percorrer, no sentido da automação dos sistemas de produção leiteira.

\section{REFERÊNCIAS BIBLIOGRÁFICAS}

BANZATO, E. O paradigma da automação. 2002. Disponível em: 〈http://www.guialog.com.br/Artigo.htm>. Acesso em: 10 jul. 2005.

BRANDÃO, A. S. P. Aspectos econômicos e institucionais da produção de leite no Brasil. In: VILELA, D.; BRESSAN, M.; CUNHA, A. S. Cadeia de lácteos no Brasil: restrições ao seu desenvolvimento. Juiz de Fora: Embrapa Gado de leite, 2001. p. 39-72.

BRASIL. Ministério da Agricultura, Pecuária e Abastecimento. Panorama do setor lácteo brasileiro: esse crescimento é de dar água na boca. Brasília, DF, 2004.

EMPRESA BRASILEIRA DE PESQUISAAGROPECUÁRIA. Automação de processos. Juiz de Fora, 1996. Disponível em: <http://cnpdia.embrapa.br/menuleft-desenv-linhasauto.html>. Acesso em: 13 jul. 2005.

FARIA, V. P. Avanços e desafios em P\&D no segmento da produção da cadeia agroalimentar do leite no Brasil. In: VILELA, D.; BRESSAN, M.; CUNHA, A. S. Cadeia de lácteos no Brasil: restrições ao seu desenvolvimento. Juiz de fora: Embrapa Gado de leite, 2001. p. 165-213.

INSTITUTO BRASILEIRO DE GEOGRAFIA E ESTATÍSTICA. Sistema IBGE de recuperação automática -SIDRA. 2003. Disponível em: 〈http://www.ibge.gov.br〉. Acesso em: 14 mar. 2004.

LOPES, M. A. Informática aplicada à bovinocultura. Jaboticabal: FUNEP, 1997. 82 p.

VILELA, D. Perspectivas para a produção de leite no Brasil. In: TEIXEIRA, J. C.; DAVID, F. M.; ANDRADE, G. A.; ÍTALO NETO, A.; TEIXEIRAS, L. F. A. C. Avanços em produção e manejo de bovinos leiteiros. Lavras: UFLA, 2002. p. 225-262. 